\title{
A comparação da estrutura social de turmas de graduação e pós-graduação: Um entendimento da cartografia dos grupos
}

\author{
Edgar Reyes J unior \& Maria de Lourdes Borges - Universidade do Vale do Rio
} dos Sinos - Unisinos, São Leopoldo - RS, Brasil ${ }^{1}$

\begin{abstract}
Resumo
Diversos cientistas lançaram-se em busca de explicações para o fenômeno dos grupos. O que se propõe aqui é a possibilidade da utilização do software Ucinet 6.0 e Pajek 1.10 para demonstrar a denominada 'cartografia' de dois grupos acadêmicos. Pretende-se colaborar com o entendimento das relações de tais grupos em favor de um melhor aproveitamento acadêmico. A estrutura de relações entre os estudantes destes grupos acadêmicos pode influenciar na capacidade de aprendizado e na produção destes grupos. Por meio da análise de redes sociais, se objetivou verificar estas estruturas de relações. Metodologicamente, uma survey, aplicada uma turma de pós-graduação e em uma de graduação em administração. Com o uso dos softwares, suas redes de relações foram elaboradas, sendo possível desta maneira, verificar as características estruturais e posicionais da rede e dos alunos nela. Verificou-se que a densidade de turmas menores, como a de pósgraduação é maior, assim como são menores suas distâncias. Foi observado ainda que os alunos mais centrais, tendem a ter melhor aproveitamento acadêmico e alunos mais isolados tendem a ter maior dificuldades de desempenho. Percebe-se que a análise de redes sociais pode ser um bom instrumento de avaliação dos alunos.
\end{abstract}

Palabras clave: Aproveitamento académico - análise de redes sociais.

\begin{abstract}
Different scientist tried to explain the dynamics of small groups. This paper present the application of Ucinet 6.0 and Pajek 1.10 for getting a "cartography" of two academic groups with the aim of showing how the structure of relationships affects the academic outcomes. Through a survey applied to one group of undergraduate students and other group of graduate students (both in Management sciences) and the analysis of the pattern of relationships we found that more central students had better results that the periferic ones. This finding suggests the possibility of using social network analysis as a tool for student's assessment.
\end{abstract}

Key words: Academic performance - social network analysis.

\section{I ntrodução}

Vários cientistas (Parsons \& Bales, 1970; Mills, 1970; Lewin, 1991; Moreno, 1962; Coch \& French jr., 1948; Mailhiot, 1991; entre outros) lançaram-se em busca de explicações para o fenômeno dos grupos. O que se propõe aqui é a possibilidade da utilização do software Ucinet 6.0 para demonstrar a denominada 'cartografia' de 
dois grupos acadêmicos. Denomina-se aqui cartografia, um artefato semelhante a um mapa das relações entre os membros dos grupos aqui analisados, bem como as relações de aproximação entre os membros, influência, dependência e fragmentação. Pretende-se colaborar com o entendimento das relações de tais grupos em favor de um melhor aproveitamento acadêmico.

Assim, diante da emergência da necessidade de ferramentas mais ágeis que possam indicar a configuração de um grupo, admite-se, neste estudo, que a 'cartografia' do grupo pode ser explicada através do método de análise de redes sociais aqui apresentado, uma vez que não se pretende revelar as leis internas de sua dinâmica, nem os processos de sua evolução. Pretende-se, isto sim, fornecer ao pesquisador uma fotografia dos relacionamentos existentes naquele momento dentro de determinado grupo, levando-se em consideração as relações de poder e liderança, bem como as estruturas sociais ali existentes.

Pode-se conjeturar que alunos de graduação e pós-graduação ajam como trabalhadores do conhecimento, uma vez que estes necessitam condicionarem seus esforços como parte de uma equipe organizacional (Goleman, 1995). Ao considerar a definição de grupo como um conjunto de duas ou mais pessoas que trabalham juntas regularmente com a intenção de atingir um ou mais objetivos comuns (Schermerhorn J r., 2003).

Os grupos formais são criados para servir a um propósito específico da organização e podem ser de natureza permanente ou temporária (Schermerhorn J r., 2003). Observa-se que cursos de graduação e pós-graduação possuem natureza temporária uma vez que a duração dos mesmos é estabelecida oficialmente. Como os grupos são primeiramente formais, haviam condições para que grupos informais fossem criados. Os grupos informais não são oficiais e surgem sem ter sido formalmente criados para servir a um propósito organizacional. As suas origens são espontâneas e pessoais, com base nas relações interpessoais (Schermerhorn Jr., 2003).

Dentre os grupos informais há os grupos de amizade em que se formam entre as pessoas que têm afinidades naturais, as quais tendem a trabalhar juntas, sentar-se juntas, andar juntas éter até um contato social fora do ambiente de trabalho. Há também dentre os grupos informais os grupos de interesse que se formam entre as pessoas que compartilham interesses comuns (Schermerhorn Jr., 2003). O autor

\footnotetext{
${ }^{1}$ Enviar correspondencia a: edgarreyes2000@yahoo.com.br y maluborg@gmail.com.
} 
acrescenta que uma função importante do grupo informal é ajudar as pessoas a realizarem seu trabalho, pois o grupo oferece uma rede de relacionamento interpessoal que tem o potencial de acelerar o fluxo de trabalho ou obter favores de modo mais informal, os quais não seriam possíveis pelas vias formais.

Por outro lado, o conhecimento científico é fruto de uma ação social e influenciado pelos pares que compõem estruturalmente a rede de relações dos pesquisadores, o que se pretende é, alem, da descrição destes relacionamentos, entender como os mesmos se estruturam estrutura afeta na produção do conhecimento. Para isso analisou-se a rede social de uma turma de alunos de pós-graduação, do curso de mestrado em administração da universidade do Rio dos Sinos e uma turma de graduação em Administração da mesma instituição, no intuito de investigar a seguinte questão:

- Quais as diferenças na estrutura social de turmas de graduação e pósgraduação e seus impactos acadêmicos?

Para responder a questão este estudo está estruturado em cinco seções. Após uma breve introdução, contendo o objetivo, são apresentados os conceitos teóricos relacionados à análise de redes sociais, que nortearam a pesquisa. Posteriormente, são discutidos os procedimentos metodológicos. Por fim, têm-se os resultados e as considerações finais do estudo.

\section{Revisão teórica}

\subsection{Contextualização: o estudo dos pequenos grupos}

A socialização dos pequenos grupos fez parte do interesse científico a partir dos sociólogos do século XIX tais como Durkheim e Simmel (MILLS, 1970). Deve-se observar que Cooley (1909 apud MILLS, 1970) já enfatizava a dificuldade de reconhecer as ligações existentes dentro dos pequenos grupos. Porém o maior interesse pelos fenômenos que ocorrem em um grupo foi através dos estudos de Mayo e Roethlisberger (BURREL \& MORGAN, 1998), através das descobertas dos estudos de Hawthorne que procuraram enfatizar os fatores sociais do traba $\neg$ lho, externos e internos, como influentes nas atitudes dos emprega $\neg$ dos e na eficiência do trabalho. A partir desta conclusão eles focalizaram estes fatores em suas subseqüentes investigações e análises e iden $\neg$ tificaram as noções de organização 'formal' e 'informal' e das con $\neg$ tribuições feitas por fatores sociais ao equilíbrio no local de trabalho. 
Moreno (1962), por sua vez identificou a importância das relações emocionais entre os membros, o que facilitava a representação e a comparação entre os padrões de tais relações. Mas, o pai da dinâmica de grupo é Kurt Lewin (1965) que trouxe uma abordagem mais rigorosa ao método experimental das ciências sociais, pois para ele, o comportamento social obedece a leis, as quais devem ser obtidas a partir do conhecimento de campo de forças sociais e psicológicas que atuam como causas de comportamento. A ciência dos grupos depende da localização e da mensuração de tais forças.

Segundo Mailhiot (1991), Lewin considera que não há diagnóstico de uma situação social concreta que possa ser formulado sem a exploração da dinâmica própria do grupo implicado. Assim, neste entendimento, a dinâmica própria de um grupo não se revelará realmente, senão ao pesquisador que tenha conseguido assimilar todos os dados concretos da vida desse grupo. Ou seja, os fenômenos de um grupo não revelam as leis internas de sua dinâmica, senão aos pesquisadores dispostos a se engajar pessoalmente nos processos de evolução do grupo, como participante e observador.

Por ocasião da Segunda Guerra Mundial, impulsionados pela necessidade de trabalhar técnica e psiquicamente com grupos, vários cientistas sociais lançaram-se na explicação dos fenômenos característicos dos grupos sociais, tais como Deutsch, Bavelas, Festinger (MILLS, 1970), porém foi Parsons \& Bales (1970) quem apresentou uma teoria sociológica de interação do grupo. Nessa teoria, para que o grupo consiga atuar durante certo tempo, é preciso que o grupo se adapte às realidades da situação imediata, tais como, atingir ao objetivo do grupo, manter o grupo unido, satisfazer as necessidades dos membros.

O grupo era entendido, por Parsons \& Bales (1970) como um sistema social em miniatura, por isso os grupos enfrentam problemas típicos do sistema, ou seja, ao invés de compreender o efeito do grupo sobre a pessoa, os autores observaram os efeitos dessas variáveis sobre o grupo: é o grupo que deve ser descrito e explicado, o que proporcionou pensar os grupos em termos mais abstratos e gerais. Isto estimulou a busca por modelos mais abstratos e matemáticos no entendimento dos processos grupais. 
Mills (1970) por sua vez, destaca que o pesquisador deve manter certa distância do fenômeno que ocorre nos grupos estudados, pois para tornar possível sua ciência, o pesquisador precisa adquirir um ponto de vista intelectual que transcenda as fronteiras do grupo (estar dentro ou fora), e assim, tornar possível seu estudo.

Portanto, conforme o pensamento de Lewin (apud MAILHIOT, 1991), um pesquisador só pode compreender a dinâmica de um grupo se o acompanhar como participante e observador, porém para Lewin, a ciência dos grupos depende da localização e da mensuração do campo de forças sociais e psicológicas que atuam no comportamento.

Já para Mills (1970), o pesquisador precisa sim manter certa distância do fenômeno que está estudando, para preservar a acurácia do estudo. Porém com o importante estudo de Parsons \& Bales (1970), a partir da visão da teoria dos sistemas, foi trazido uma nova visão ao entendimento dos grupos. Para eles, o grupo que deve ser descrito e explicado, o que proporcionou pensar os grupos em termos mais abstratos e gerais, o que possibilitou e motivou a busca por modelos matemáticos e mais abstratos. É dentro desta lógica que este estudo se insere, uma vez que aqui é proposta o que foi chamada de cartografia dos pequenos grupos, por fornecer, através da metodologia adotada, uma fotografia dos grupos no que diz respeito à intensidade das relações, aproximação, dependência, fragmentação etc.

\subsection{Coompetição: cooperar para competir}

Altruísmo é caracterizado quando o indivíduo é motivado a atuar de forma voluntária visando o benefício de outras pessoas, sem a perspectiva aparente de ganhos pessoais, à exceção da auto-recompensa (PALMIERI \& BRANCO, 2004). A cooperação e a competição são aspectos de um mesmo fenômeno relacional e estão a serviço de objetivos individuais que vão sendo constituídos em contextos grupais determinados, que ora favorecem a cooperação, ora a competição (EDWARDS, 1991). Na turma pode-se perceber a existência de um contexto colaborativo, através de grupos virtuais de discussão e grupos de estudo, além da constante preocupação demonstrada pelos alunos com seus colegas.

Deutsch (1949) define a cooperação como o contexto interativo em que as ações de um participante favorecem o alcance de objetivo comum a outros. Já a competição é caracterizada como a busca de objetivos mutuamente exclusivos, ou seja, quanto mais um indivíduo se aproxima de seu objetivo, mais o outro se afasta da possibilidade de alcançar o seu. Isto significa que contextos cooperativos 
tendem a facilitar ou promover dinâmicas interacionais cooperativas. No caso da turma houve cooperação intra-grupo porque o alcance dos objetivos individuais não constituía um trade-off, ou seja, quando um componente dividia com os outros alguma meta acadêmica, isto não o afastava de atingir seu objetivo e ainda conseguia aprovação social, em um círculo virtuoso de motivações para outros comportamentos pró-sociais. Este foi o contexto formado resultando em pulverização de atores com centralidade, capacidade de informação, mediadores, poder e centrais. Não deve-se subestimar a influência do poder de conectividade, no caso, o grupo de discussão, uma vez que todos mandavam e-mail para todos e sua contribuição na formação do contexto de cooperação. A análise de Deutsch (1949) contribui, particularmente, para chamar a atenção para a importância do contexto, com suas regras e expectativas sociais.

As causas da cooperação, neste grupo especificamente, deveram-se à motivação de enfrentamento coletivo de alta carga de estresse próprias dos cursos de mestrado devido a um forte ritmo imposto a todos, somados com a carga horária diária laboral de cada um. O estresse é uma reação intensa do organismo frente a qualquer evento bom ou mau que altere a vida do indivíduo. Essa reação ocorre, em geral, frente à necessidade de adaptação exigida do indivíduo em momentos de mudança (Everly, 1989).

Na pesquisa de Schillings (2005) os resultados mostram que os relacionamentos estabelecidos pelos mestrandos com seus colegas e professores foram geradores de estresse, pois os índices mais elevados estão entre os alunos que consideram insatisfatórias estas relações. Schillings também verificou que o tempo para efetuar as leituras do mestrado foi considerado insuficiente pela maioria dos sujeitos e foi a maior incidência de estresse quanto mais insuficiente este tempo. Conforme a pesquisa de Schillings (2005) demonstra, nesta turma de administração a cooperação ajudou a diminuir o estresse, uma vez que a turma demonstrou estar com satisfatório grau de satisfação com as amizades, através dos enlaces dos atores.

Observa-se que os atores constituintes da turma de mestrado apresentam características distintas sob o ponto de vista demográfico (sexo, idade, etnia), diferenças quanto às aptidões e habilidades (o que uma pessoa é capaz ou pode fazer) e características de personalidade (os vários traços que refletem como a pessoa é), bem como valores e atitudes distintos (Schermerhorn Jr. et al., 2003). Os atores deveriam estar sentindo-se com segurança sobre seu autoconceito e auto-estima, uma vez que não entraram em confronto ou em disputas abertas por 
liderança. Segundo Schermerhorn Jr. et al. (2003) há dois tipos de teoria de liderança. $\mathrm{Na}$ liderança tradicional as abordagens das características, do comportamento e da contingência situacional, enquanto que a nova liderança focaliza enfatiza uma combinação do carisma, visão e mudança.

Por outro lado, as equipes de alto desempenho têm fortes valores de núcleo que ajudam a guiar as atitudes e o comportamento para a direção adequada ao propósito da equipe. Esses valores agem como um sistema de controle interno do grupo ou equipe e podem substituir grande parte da direção externa propiciada por um líder. Além disto, estas equipes transformam um senso geral de propósito em objetivos específicos de desempenho através do comprometimento com resultados específicos, ajudando os membros a compreender a necessidade de esforço coletivo ao invés de individual. Finalmente os membros das equipes de alto desempenho têm o conjunto certo de habilidades, assim como têm criatividade (Kartzenbach \& Smith 1993). Em equipes de alto desempenho a liderança nomeada deve ajudar a satisfazer as necessidades de manutenção e de apoio às relações interpessoais, e de tarefa, mas a responsabilidade pelo desempenho é compartilhada entre os membros do grupo, o que também é denominado de liderança distribuída (Schermerhorn Jr. et al., 2003). Pode-se compreender a pulverização da liderança deste grupo, uma vez que pode-se conjeturar que o grupo funcionou como uma equipe de alto desempenho em que todos se comprometeram tanto com a tarefa em si, tais como o cumprimento das metas acadêmicas de forma cooperativa, e com as necessidades de manutenção ajudando o grupo a permanecer saudável como sistema social.

\subsection{Análise de Redes Sociais}

As redes sociais são definidas como um conjunto de dois elementos: atores (pessoas, instituições ou grupos) e suas conexões (Wasserman e Faust, 1994). Emirbayer e Goodwin (1994) destacam que as redes sociais são conjuntos de contatos que ligam vários atores, que podem ser de diferentes tipos, apresentarem conteúdos diferentes, bem como diferentes propriedades estruturais. Isto porque redes sociais referem-se a um conjunto de pessoas, ou organizações, ou ainda, outras entidades sociais conectadas por relacionamentos sociais, motivados pela amizade e por relações de trabalho ou compartilhamento de informações e, por meio dessas ligações, vão construindo e re-construindo a estrutura social (Emirbayer \& Goodwin, 1994). 
A análise de redes Sociais (ARS) é uma aproximação intelectual ampla para identificar as estruturas sociais que emergem das diversas formas de relações, mas também um conjunto específico de métodos e técnicas. As tradições dominantes nas Ciências Sociais construíram modelos explicativos a partir de modelos causais, que geralmente foram aplicados a estruturas macro, sociais ou econômicas. A partir de modelos intencionais que foram utilizados para construir explicações de natureza micro, que se centravam na conduta individual. O enfoque da Psicologia Social respondeu à necessidade de conectar ambos os níveis de análise e neste sentido, a ARS, se apresenta como una ferramenta útil (Borgatti e Everett, 1996).

Desta forma pode-se definir a ARS como um conjunto de técnicas de análise para o estudo formal das relações entre atores e para analisar as estruturas sociais que surgem em decorrência dessas relações ou da ocorrência de determinados eventos. A consolidação da análise de redes veio precisamente evidenciar os efeitos que os diferentes padrões e estruturas de rede tem em relação ao acesso dos membros a recursos (Granovetter, 1973). De maneira que o acesso a recursos, de qualquer tipo, parece estar fortemente associado à forma das redes sociais.

Para Hanneman (2001), a ARS de um sistema social é, antes de tudo, um conjunto estruturado de posições sociais. O conceito de papel aparece como uma variável dependente da posição. Em conseqüência, as dimensões valorativas e normativas da conduta são, para a ARS, assim como as demais dimensões da motivação, mais efeito que causa.

Ainda de acordo com Hanneman (2001), a análise de redes sociais é mais um ramo da sociologia matemática do que uma análise estatística ou quantitativa. A idéia básica de uma rede é simples: um conjunto de atores ou nós, pontos ou agentes entre os quais existem vínculos ou relações. Pode haver muitos ou poucos atores e pode existir uma ou mais classes de relações entre eles. De maneira geral, para se entender bem a rede, deve-se conhecer as relações entre cada par de atores da população estudada. O uso de técnicas matemáticas, como matrizes e grafos, por exemplo, permite uma descrição mais adequada e concisa de suas características.

Na centralidade, as redes sociais enfatizam que o poder é baseado em relações. Um indivíduo não tem poder abstrato, somente se detém poder porque se pode influir sobre os demais. Devido ao fato de o poder ser, assim uma conseqüência dos padrões relacionais, a quantidade de poder nas diferentes estruturas sociais pode variar de forma que é uma propriedade sistêmica (macro) e relacional (micro) (Hanneman, 2001). 
A maneira como um ator encontra-se inserido em uma rede relacional determina assim a medida das restrições e oportunidades que lhe é apresentada. Os atores que enfrentam menos restrições e tem mais oportunidades estão em posições estruturais mais favoráveis Uma posição mais favorável significa ter melhores ofertas além de ser um foco da deferência e atenção daqueles em posição menos favorável (Emirbayer \& Goodwin, 1994).

Um ator é localmente central se ele apresenta um grande número de conexões com outros pontos, e será globalmente central se possuir uma posição significantemente estratégica na rede como um todo (Scott, 2000). Rodrigues e Mérida (2006) identificam através dela os atores mais centrais, mais proeminentes, mais poderosos e com prestigio.

A abordagem relacional foca as conexões diretas e indiretas entre os atores (Emirbayer \& Goodwin, 1994), para entender comportamentos e processos por meio da conectividade entre os atores. Para tanto, foram utilizadas as medidas de densidade, distância, grau de centralidade, centralidade de intermediação e centralidade geodésica e coesão social para cada uma das dimensões consideradas.

Para Hannemam (2001), os subgrupos existentes em uma rede têm suas próprias normas, valores, orientações, sendo base para a solidariedade e o comportamento coletivo dentro do grupo. Wasserman e Faust (1994) afirmam que os subgrupos apresentam como propriedades gerais, a mutualidade e a freqüência dos laços, a proximidade e alcance entre membros dos subgrupos, e a freqüência relativa de laços entre membros fora e dentro dos subgrupos. Este conjunto de indicadores será analisado de forma pormenorizada na metodologia.

\section{Procedimentos metodológicos}

Este estudo pode ser definido como descritivo por buscar apresentar as propriedades estruturais e posicionais de uma turma de mestrandos e de uma de graduação em administração em relação aos seus pares. A pesquisa, todavia, também é explicativa, já que tem como principal objetivo tornar algo inteligível, ou explicar seus motivos. Visa, assim, esclarecer possíveis fatores que contribuem, e de que forma na ocorrência de um dado fenômeno. Os dados coletados para esta pesquisa foram essencialmente dados primários e de corte transversal. 
O método de pesquisa empregado foi quantitativo, mais especificamente questionário de análise redes sociais, que possibilita avaliar tanto os aspectos descritivos dos relacionamentos, quanto às análises estatísticas causais de tais fenômenos (Hanneman, 2001; Wasserman \& Faust, 1994). Escolheu-se utilizar o método de análise de redes sociais por este incluir informações sobre o relacionamento entre os alunos e pela pertinência do método na análise de outros fenômenos sociais no futuro. Este estudo é censitário, já que os 24 alunos de pósgraduação e os 42 alunos de graduação foram questionados.

A estratégia empregada para coleta de dados foi Survey em que se questionou aos alunos quanto às relações que foram criadas durante o período de aulas com os demais colegas, avaliando aqueles com os quais se criaram relações de amizade e aqueles em que havia alguma forma de relação afetiva, definida como "conhecidos próximos".

Todos os dados foram tabulados com o uso do software Microsoft Excel ${ }^{\circledR}$. Para efeitos de tabulação dos dados não foram feitas distinções de peso entre as formas de relacionamento entre os alunos, quer de amizade ou de afinidade, até pela dificuldade encontrada pelos respondentes em promover tal distinção. Os dados dos questionários foram transportados então para uma matriz quadrática.

A Análise dos dados foi toda feita por meio dos softwares UCInet 6.0 e NetDraw 2.0461. A sistemática e a seqüência da análise baseou-se em Rodríguez e Mérida (2006). Para que se possa fazer uma comparação entre os resultados de ambas as turmas, foram sempre considerados os valores normalizados.Os nomes não são mencionados, mas substituídos por números dispostos de maneira aleatória no intuito de proteger a identidade dos respondentes.

Basicamente a ARS operacionaliza o estudo das relações a partir do estudo de sociogramas matriciais, da existência ou não se relação, mediante a inclusão de 0 para inexistência de relação entre os atores e 1 para relação existente. Daí obtémse matrizes simétricas binárias, do tipo $A^{*} A^{\prime}$ já que todos os atores relacionados são também citados e dispostos ordenadamente, e somente existem duas possibilidades de vínculo, existência ou não de relação (Molina, 2001).

Para se analisar individualmente cada ator, foram utilizadas diferentes medidas de centralidade, nomeadamente, o grau de centralidade, o grau de intermediação e a centralidade geodésica. O grau de centralidade (Degree) é utilizado em redes simétricas que se manifesta pelas relações diretas de cada ator (RODRIGUES E 
MÉRIDA, 2006). Ela é medida pelo número de laços diretos que um ator possui com outros demais em uma rede (Wasserman \& faust, 1994).

\section{Análise e discussão dos resultados}

\subsection{Densidade}

Mede a proporção de relações existentes sobre o total de relações possíveis. Indica a intensidade de relações em um conjunto da rede, pelo uso de uma matriz dicotômica a partir de uma imagem de matriz binária, com matriz de pré-imagem ator-ator. Significa que na turma de pós-graduação, dos relacionamentos possíveis, $30,62 \%$ são existentes. Na turma de graduação este percentual caiu para $16 \%$, ou seja, as relações sociais na turma de graduação analisadas eram muito mais débeis.

\subsection{Distância}

Indicam o esforço para que um ator alcance outro. A Distância Geodésica (Averange distance) é número de relações no caminho mais curto entre dois atores. Na pós-graduação 1,893 é a distância média mais curta existente entre os alunos em um sistema de relações de apoio e contato. Este valor sobe para 2,323 na turma de graduação, indicando que também aí os alunos de graduação encontramse socialmente mais afastados que os de pós-graduação.

\subsection{Centralidade}

Estuda os atores mais centrais, mais proeminentes, mais poderosos e com prestigio. Utilizam-se vários indicadores, sendo que cada um transmite informações específicas de poder. O grau de centralidade é utilizado em redes simétricas, como nos casos analisados, que se manifesta pelas relações diretas de cada ator (Rodrigues \& Mérida, 2006). A Figura 1 é a representa a estrutura relacional da turma de pós-graduação analisada. Nela pode-se observar a grande centralidade de um grupo de 6 alunos, nomeadamente 33,31, 37, 41, 9 e 11, ao mesmo tempo em que se observa um afastamento especialmente alto dos alunos 17 e 25 . 


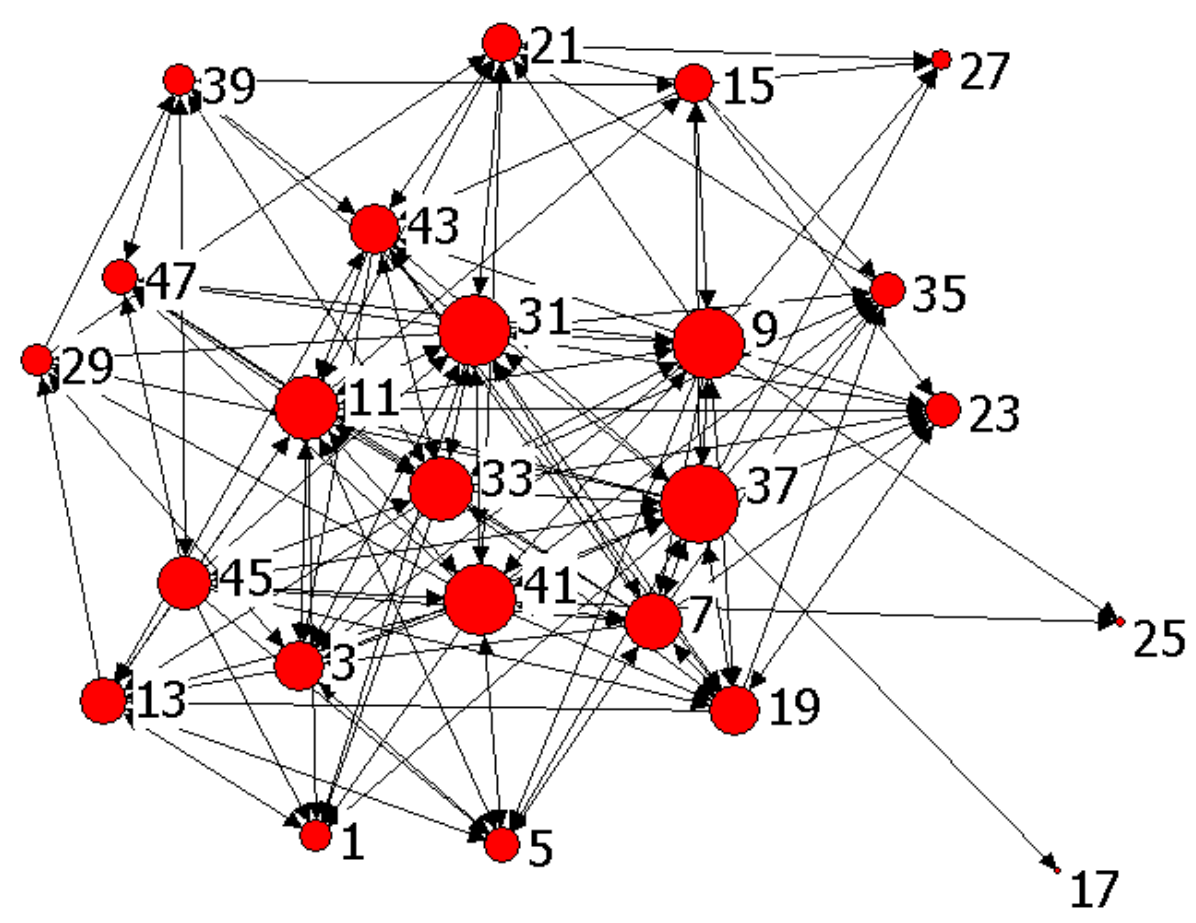

Figura 1. Mapa relacional da Turma de Pós-graduação.

A Figura 2 por sua vez apresenta a estrutura relacional da turma de graduação. Apesar do número de alunos desta turma ser maior, observa-se uma pulverização bastante maior dos alunos relacionalmente centrais, não havendo aparentemente uma elevada dependência de algum aluno em especial. Ao mesmo tempo observase um numero maior de alunos mais afastados do grupo principal, ou seja, com baixo nível de integração com os demais colegas. 


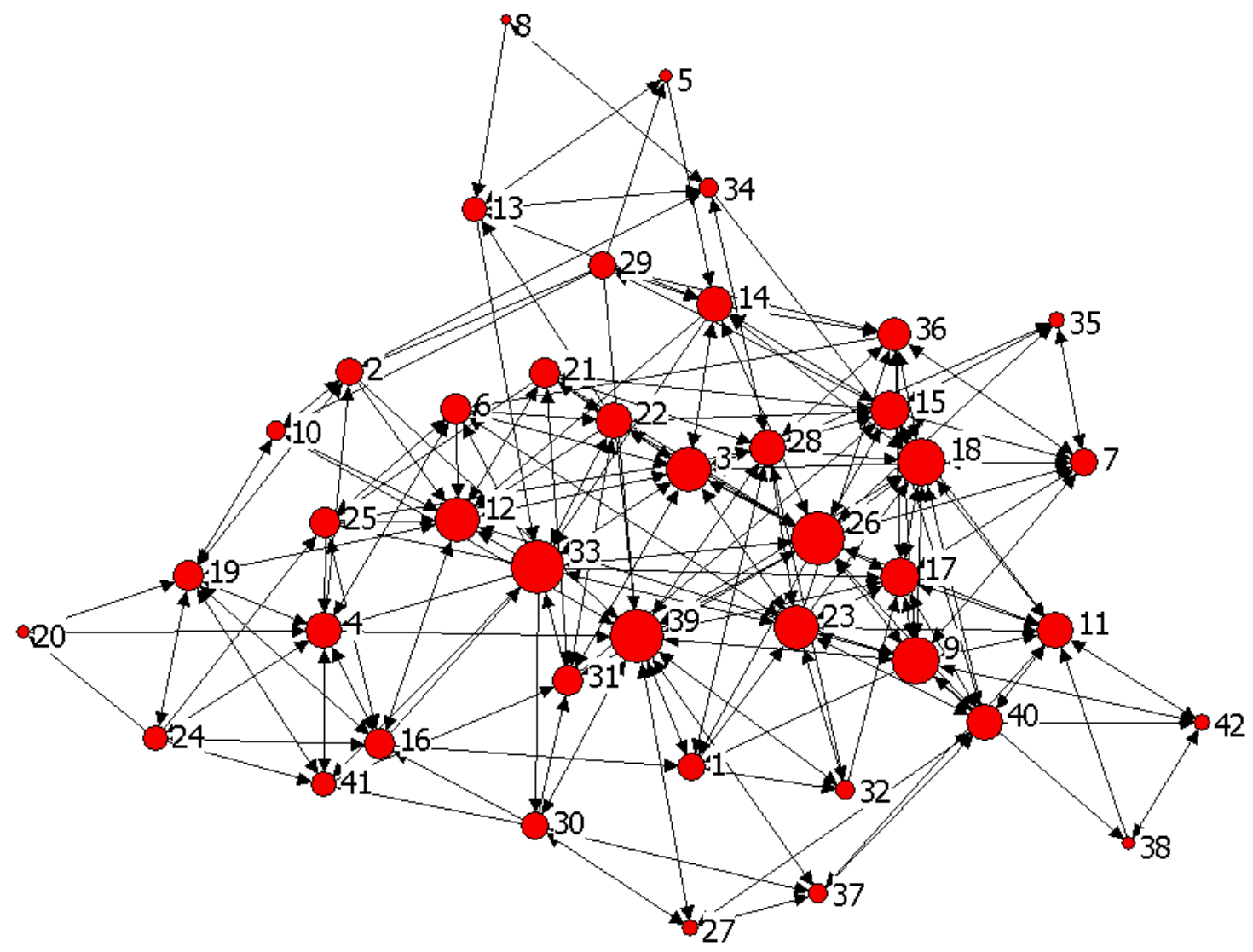

Figura 2. Mapa relacional da Turma de Graduação.

\subsubsection{Grau de centralidade}

O grau de centralidade (Degree) é utilizado em redes simétricas que se manifesta pelas relações diretas de cada ator (Rodrigues \& Mérida, 2006). Ela é medida pelo número de laços diretos que um ator possui com outros demais em uma rede (Wasserman \& Faust, 1994).

\begin{tabular}{|c|r|r|r|r|r|r|c|}
\hline Ator & \multicolumn{1}{|c|}{ Grau } & $\begin{array}{c}\text { Grau } \\
\text { Normal }\end{array}$ & Participação & & Grau & $\begin{array}{c}\text { Grau } \\
\text { Normal }\end{array}$ & Participação \\
\hline 37 & 18,000 & 78,261 & 0,074 & Média & 10,083 & 43,841 & 0,042 \\
\hline 09 & 16,000 & 69,565 & 0,066 & Desvio Padrão & 4,396 & 19,114 & 0,018 \\
\hline 41 & 16,000 & 69,565 & 0,066 & Mínino & 1,000 & 4,348 & 0,004 \\
\hline 31 & 16,000 & 69,565 & 0,066 & Máximo & 18,000 & 78,261 & 0,074 \\
\hline 27 & 04,000 & 17,391 & 0,017 & Centrali. da rede & $37,55 \%$ & & \\
\hline 25 & 04,000 & 8,696 & 0,008 & Heterogeneidade & $4,96 \%$ & & \\
\hline 17 & 01,000 & 4,348 & 0,004 & Normalizado & $0,83 \%$ & & \\
\hline
\end{tabular}

Quadro 1. Grau de centralidade representativas da turma de pós-graduação. 
O grau de centralidade (degree) dos alunos de pós-graduação é de 37,55\% com máximo de 78.261 para o ator 37, seguido pelos atores 09,41 e 31, com 69.565, quarteto que forma o núcleo de centralidade da pós-graduação. Como mínimo temos o ator 17 com 4,348, seguido do ator 25 com 8.696 e por 27 com 17.391 contatos, sendo assim os elementos mais afastados do grupo (Quadro 1). O aluno 17, após 14 meses de mestrado abandonou o curso. Talvez sua posição na estrutura social da turma já fosse representativa desta situação.

Na turma de graduação, o grau de centralidade, apresentado no quadro 2, é de $17,56 \%$, sugerindo que o grupo o grupo tem uma liderança mais dispersa e menos dependente de alguns elementos determinados. Tal hipótese é confirmada ao se observar que 10 alunos encontram-se com valores muito próximos de centralidade (entre 36.585 e 29.829), valores bastante mais baixos, todavia que na turma de pós-graduação.

\begin{tabular}{|c|c|c|c|c|c|c|c|}
\hline Ator & Grau & $\begin{array}{c}\text { Grau } \\
\text { Normal }\end{array}$ & Participação & & Grau & $\begin{array}{c}\text { Grau } \\
\text { Normal }\end{array}$ & Participação \\
\hline 39 & 15,000 & 36,585 & 0,044 & Média & 8,143 & 19,861 & 0,024 \\
\hline 33 & 15,000 & 36,585 & 0,044 & Desvio Padrão & 3,447 & 8,408 & 0,010 \\
\hline 26 & 15,000 & 36,585 & 0,044 & Mínino & 2,000 & 4,878 & 0,006 \\
\hline 09 & 13,000 & 31,707 & 0,038 & Máximo & 15,000 & 36,585 & 0,044 \\
\hline 18 & 13,000 & 31,707 & 0,038 & Centrali. da rede & $17,56 \%$ & & \\
\hline 03 & 12,000 & 29,268 & 0,035 & Heterogeneidade & $2,81 \%$ & & \\
\hline 23 & 12,000 & 29,268 & 0,035 & Normalizado & $0,44 \%$ & & \\
\hline 12 & 12,000 & 29,268 & 0,035 & & & & \\
\hline 15 & 11,000 & 26,829 & 0,032 & & & & \\
\hline 17 & 11,000 & 26,829 & 0,032 & & & & \\
\hline 20 & 3,000 & 7,317 & 0,009 & & & & \\
\hline 05 & 3,000 & 7,317 & 0,009 & & & & \\
\hline 38 & 3,000 & 7,317 & 0,009 & & & & \\
\hline 08 & 2,000 & 4,878 & 0,006 & & & & \\
\hline
\end{tabular}

Quadro 2. Grau de Centralidade representativas da turma de graduação.

Da mesma forma, o número de alunos mais distantes do grupo é maior e com valores igualmente baixos (entre 4.878 e 7.317), sem todavia apresentar um aluno semi-desconectado, como aparece na pós-graduação (aluno 17).

\subsubsection{Indicador de Poder (Bonacich power)}

O índice de poder de Bonacich defende que a centralidade de cada ator é uma função relacionada à quantidade de conexões de cada ator e de quantas conexões os atores próximos a ele possuem. Quanto menores estas forem as conexões dos atores próximos, maior será o poder do ator. O quadro 3 representa este índice na turma de pós-graduação. Nesta turma observa-se com grande clareza a formação 
de dois grupos, um formado por alunos com poder superior a 6.0 (alunos 07, 09, $11,31,33,37,41,45$ ) e os demais, com índice inferior a 4.4 , havendo inclusive 4 alunos com valores inferiores a 1.0 .

\begin{tabular}{|c|c|c|}
\hline Ator & Poder & $\begin{array}{c}\text { Poder } \\
\text { Normal }\end{array}$ \\
\hline 01 & 1,000 & 0,550 \\
\hline 03 & 6,000 & 3,301 \\
\hline 05 & 6,000 & 3,301 \\
\hline 07 & 12,000 & 6,602 \\
\hline 09 & 16,000 & 8,803 \\
\hline 11 & 11,000 & 6,052 \\
\hline 13 & 4,000 & 2,201 \\
\hline 15 & 7,000 & 3,854 \\
\hline 17 & 0,000 & 0,000 \\
\hline 19 & 8,000 & 4,401 \\
\hline 21 & 4,000 & 2,201 \\
\hline 23 & 3,000 & 1,650 \\
\hline
\end{tabular}

\begin{tabular}{|c|c|c|}
\hline Ator & Poder & $\begin{array}{c}\text { Poder } \\
\text { Normal }\end{array}$ \\
\hline 25 & 0,000 & 0,000 \\
\hline 27 & 1,000 & 0,550 \\
\hline 29 & 3,000 & 1,650 \\
\hline 31 & 15,000 & 8,252 \\
\hline 33 & 14,000 & 7,702 \\
\hline 35 & 1,000 & 0,550 \\
\hline 37 & 17,000 & 9,353 \\
\hline 39 & 5,000 & 2,751 \\
\hline 41 & 15,000 & 8,252 \\
\hline 43 & 6,000 & 3,301 \\
\hline 45 & 12,000 & 6,602 \\
\hline 47 & 2,000 & 1,100 \\
\hline
\end{tabular}

Quadro 3. Indice de Poder Bonacich na turma de Pós-graduação.

Com exceção do aluno 01 , todas as demais publicações produzidas durante 0 mestrado foram produzidas pelos alunos constantes do primeiro grupo, o que pode levar a crer que um maior índice de poder possa indicar uma maior capacidade de produção acadêmica.

\begin{tabular}{|c|c|c|}
\hline Ator & Poder & $\begin{array}{c}\text { Poder } \\
\text { Normal }\end{array}$ \\
\hline 01 & 4,000 & 3,534 \\
\hline 02 & 5,000 & 4,417 \\
\hline 03 & 11,000 & 9,718 \\
\hline 04 & 8,000 & 7,068 \\
\hline 05 & 2,000 & 1,767 \\
\hline 6 & 6,000 & 5,301 \\
\hline 7 & 7,000 & 6,184 \\
\hline 8 & 2,000 & 1,767 \\
\hline 9 & 13,000 & 11,485 \\
\hline 10 & 4,000 & 3,534 \\
\hline 11 & 9,000 & 7,951 \\
\hline 12 & 7,000 & 6,184 \\
\hline 13 & 4,000 & 3,534 \\
\hline 14 & 9,000 & 7,951 \\
\hline
\end{tabular}

\begin{tabular}{|c|c|c|}
\hline Ator & Poder & $\begin{array}{c}\text { Poder } \\
\text { Normal }\end{array}$ \\
\hline 15 & 10,000 & 8,835 \\
\hline 16 & 7,000 & 6,184 \\
\hline 17 & 8,000 & 7,068 \\
\hline 18 & 9,000 & 7,951 \\
\hline 19 & 8,000 & 7,068 \\
\hline 20 & 2,000 & 1,767 \\
\hline 21 & 7,000 & 6,184 \\
\hline 22 & 10,000 & 8,835 \\
\hline 23 & 9,000 & 7,951 \\
\hline 24 & 6,000 & 5,301 \\
\hline 25 & 5,000 & 4,417 \\
\hline 26 & 14,000 & 12,369 \\
\hline 27 & 4,000 & 3,534 \\
\hline 28 & 9,000 & 7,951 \\
\hline
\end{tabular}

\begin{tabular}{|c|c|c|}
\hline Ator & Poder & $\begin{array}{c}\text { Poder } \\
\text { Normal }\end{array}$ \\
\hline 29 & 6,000 & 5,301 \\
\hline 30 & 6,000 & 5,301 \\
\hline 31 & 6,000 & 5,301 \\
\hline 32 & 5,000 & 4,417 \\
\hline 33 & 11,000 & 9,718 \\
\hline 34 & 5,000 & 4,417 \\
\hline 35 & 4,000 & 3,534 \\
\hline 36 & 8,000 & 7,068 \\
\hline 37 & 4,000 & 3,534 \\
\hline 38 & 3,000 & 2,650 \\
\hline 39 & 10,000 & 8,835 \\
\hline 40 & 9,000 & 7,951 \\
\hline 41 & 3,000 & 2,650 \\
\hline 42 & 3,000 & 2,650 \\
\hline
\end{tabular}

Quadro 4. Indice de Poder Bonacich na turma de graduação. 
No caso da turma de graduação, quadro 4, não se observa a mesma possibilidade de formação de grupos por poder, já que o mesmo encontra-se centrado em dois alunos (respectivamente 26 e 9) e depois este indicador segue descendo paulatinamente, o que pode justificar uma maior homogeneidade de desempenho acadêmico na turma de graduação. Todavia os maiores expoentes em termos de desempenho no curso foram efetivamente os alunos 26 e 9.

\subsection{Subgrupos}

O estudo de subgrupos e sub estruturas da rede permite analisar o comportamento da rede e de seu conjunto em função da posição de cada ator nesses subgrupos.

\subsubsection{Cliques}

O estudo da coesão da rede se realiza mediante a análise dos cliques como indicador do centro nevrálgico da rede, isto é a estrutura mais fortemente coesa. Também é denominada de "coluna vertebral da rede". Um alto nível de coesão demonstram espaços de alta identificação e solidariedade entre os atores.

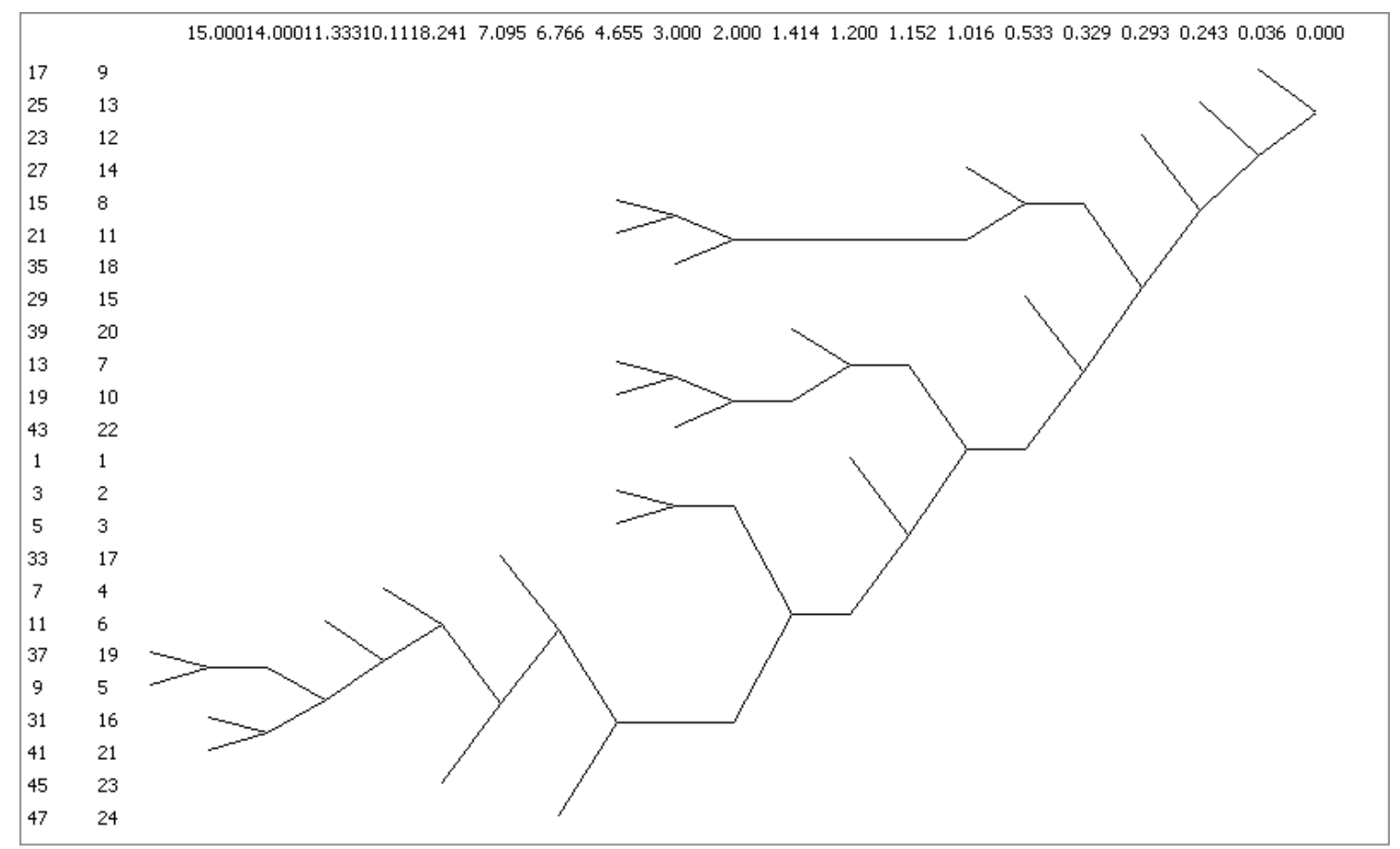

Figura 3. Cliques da turma de pós-graduação. 
A Figura 3 representa a pós graduação, com base nos pares de cliques a dupla mais coesa é formada pelos atores 37 e 09, que juntamente com os atores 07, 11, 31 e 41 forma o grupo mais coeso. Também destacam-se outros grupos, como o formado por 15, 21 e 35, o formado por 13, 09 e 43 e o par formado por 03 e 05.

No caso da turma de graduação, representado pela Figura 4, percebe-se um elevado grau de fragmentação e aparente distanciamento entre os diferentes grupos sociais que vieram a se formar na turma, fazendo com que o mesmo não apresente o aspecto de coluna vertebral, como esperado, se parecendo mais com um conjunto de galhos aparentemente pouco associados. Tal fenômeno pode se dever ao fato de o curso de graduação ser em cadeiras avulsas e nesta turma haverem alunos de 6 diferentes semestres, assim os alunos encontram-se apenas uma vez por semana e somente no horário da disciplina.

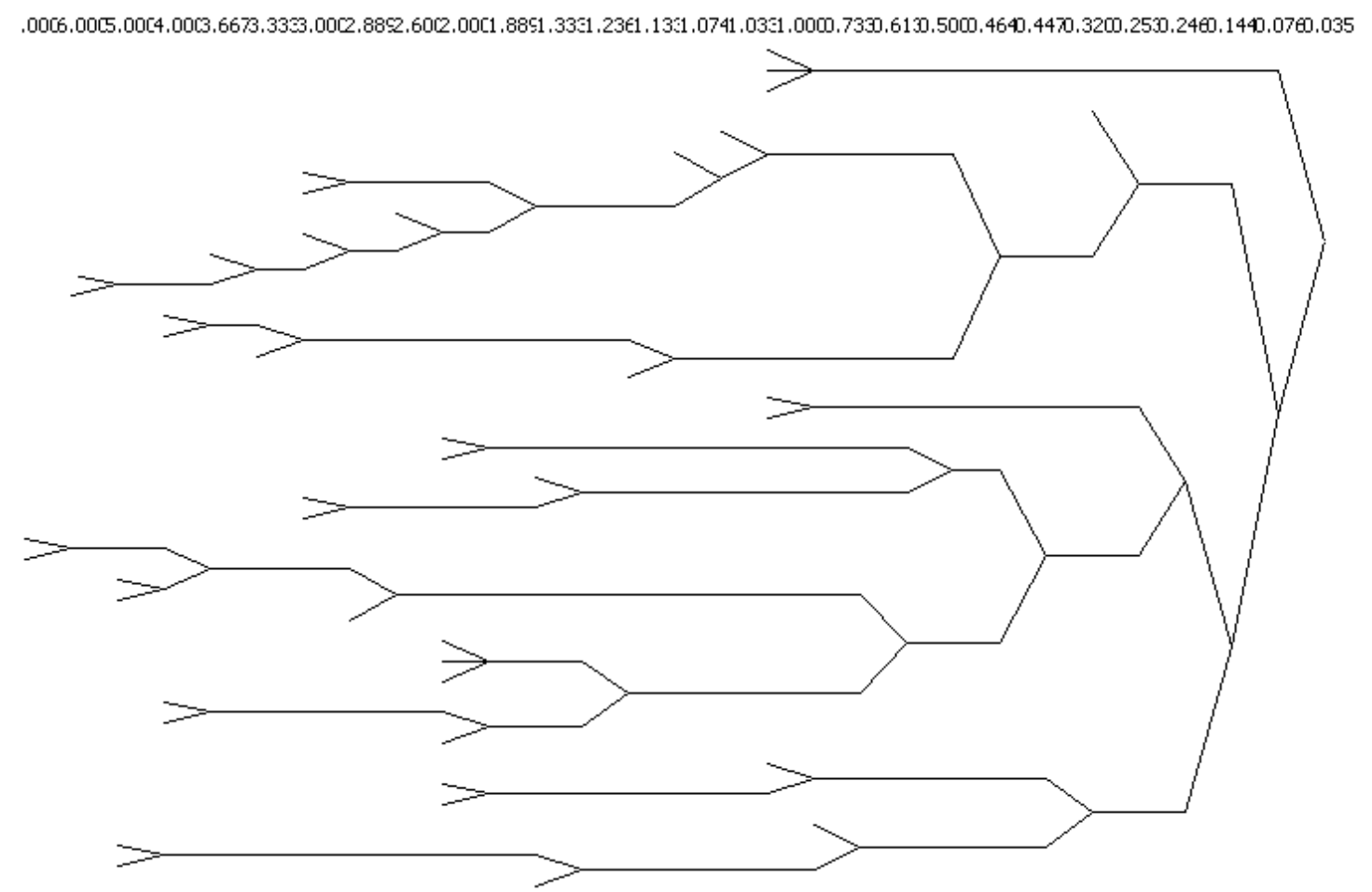

Figura 4. Cliques da turma de graduação.

\subsection{2 facções}

As facções são a divisão da rede em grupos de atores com base na similaridade de suas relações. São maximizadas as similaridades internas e minimizadas as externas com os demais grupos. 


$\begin{array}{ccccc} & 1 & 2 & 3 & 4 \\ & -\ldots .- & -.- & -\ldots & -.- \\ 1 & 0.52 & 0.11 & 0.26 & 0.05 \\ 2 & 0.11 & 0.50 & 0.10 & 0.00 \\ 3 & 0.36 & 0.35 & 0.70 & 0.23 \\ 4 & 0.05 & 0.08 & 0.03 & 0.00\end{array}$

Quadro 5. Facções da Turma de pós-graduação (4 grupos).

Optou por dividir a turma de pós-graduação em 4 grupos (Quadro 5), já que as densidades internas dos 3 primeiros grupos se apresentaram bastante altas e superiores as externas. Mas o quarto grupo não apresentou relacionamento interno, demonstrando ser este grupo formado por atores distantes da rede e conseqüentemente entre si, nomeadamente os atores 17,25 e 29 .

\begin{tabular}{|c|c|c|c|c|c|c|c|c|}
\hline & 1 & 2 & 3 & 4 & 5 & 6 & 7 & 8 \\
\hline & - - - - & - _ - - & - - - & - _ - - & - _ - - & - - - & - _ - - & - - - \\
\hline 1 & 1.00 & $\odot .07$ & $\odot .0 \odot$ & 0.16 & $\odot . \odot \odot$ & $\odot .08$ & 0.19 & $\odot . \odot \odot$ \\
\hline 2 & $\odot .11$ & 0.83 & 0.18 & $\odot .20$ & 0.26 & $\odot .05$ & 0.14 & $\odot . \odot \odot$ \\
\hline 3 & 0.06 & 0.18 & 0.67 & $\odot . \odot 9$ & 0.15 & $\odot .0 \odot$ & $\odot . \odot \odot$ & 0.06 \\
\hline 4 & 0.16 & 0.18 & $\odot .09$ & $\odot .77$ & $\odot .08$ & $\odot .0 \odot$ & 0.13 & 0.13 \\
\hline 5 & 0.10 & 0.11 & $\odot . \odot \odot$ & $\odot .05$ & 0.50 & 0.23 & $\odot .05$ & ๑.05 \\
\hline 6 & $\odot .04$ & 0.05 & $\odot .0 \odot$ & $\odot . \odot \odot$ & 0.27 & 0.73 & $\odot . \odot 4$ & $\odot . \odot \odot$ \\
\hline 7 & $\odot .19$ & 0.11 & $\odot . \odot \odot$ & $\odot .22$ & $\odot . \odot \odot$ & $\odot . \odot \odot$ & $\odot .67$ & $\odot .06$ \\
\hline 8 & $\odot . \odot \odot$ & $\odot . \odot \odot$ & 0.13 & $\odot .16$ & ๑. 05 & $\odot . \odot \odot$ & $\odot .06$ & $\odot .33$ \\
\hline
\end{tabular}

Quadro 6. Tabela de densidade para 8 facções da Turma de Graduação.

$\mathrm{Na}$ turma de graduação, para se obter um nível de densidade interna representativa de houve a necessidade de se ampliar o número de grupos para 8 (Tabela 2). O que se identificou nesse maior fracionamento foram grupos com características muito comuns, de relacionamento mais antigo, originado da freqüência comum a outras disciplinas, entre outros, aspectos estes que confirmam as estruturas identificadas nos Cliques.

\section{Considerações finais}

Este artigo teve por objetivo analisar as diferenças relacionais entre turmas de graduação e pós-graduação analisando os impactos destas estruturas sociais sobre o desempenho acadêmico. Algumas explicações podem ser identificadas pela análise de rede social

A aparentemente mais alta densidade relacional do grupo de pós-graduação e mais curta distância entre os atores pode demonstrar um nível mais alto de coesão de grupo em relação ao de graduação. Todavia observou-se repetidamente a representação de um grupo de alunos de pós-graduação, que obtiveram maior volume de produção acadêmica como aqueles com maior centralidade, Índice de 
poder de Bonacich e todos na mesma facção. I sso pode representar a formação de um subgrupo coeso e independente dentro da turma de pós-graduação, o que também pode vir a ser um gerador de conflitos por si só.

Na turma de graduação, o mesmo não se observa, existe uma pulverização muito maior das forças dentro da turma, havendo apenas dois alunos que se destacam academicamente, sendo os dois que detém maiores valores no Índice de Bonacich, ficando assim observado que este indicador pode vir a ser representativo no que tange ao cruzamento de relações sociais e desempenho.

Todavia não se podem desconsiderar os atores mais afastados do grupo, nomeadamente 17 da turma de pós-graduação e 8 e 20 da turma de graduação que, ou abandonaram o curso algum tempo depois da realização da survey, ou não foram aprovados na disciplina, que podem, a partir das informações obtidas neste trabalho, serem alvos de ações focadas da gestão acadêmica, tanto de ordem pedagógica, como psicossocial. .

O estudo da dinâmica dos grupos merece maior atenção dos pesquisadores interessados nos seus processos e nas suas conseqüências, uma vez que interfere diretamente sobre a eficácia dos projetos nas mais variadas instituições. Especificamente, na gestão acadêmica, o entendimento da dinâmica dos grupos de estudantes torna-se vital para a promoção e manutenção do aprendizado, uma vez que pode auxiliar no entendimento

Como maior limitação encontrada neste trabalho, identifica-se a dificuldade de uma clara definição dos construtos "amizade" e "conhecido próximo", o que deixa margem a interpretações pessoais aos respondentes da Survey em relação a estes. I mportante acrescentar que cada turma encontra-se em um determinado contexto relacional e que generalizações não são possíveis, já que se trata exclusivamente da comparação entre duas turmas de alunos. Sugerem-se estudos futuros das relações existentes entre os resultados aqui apresentados e a produção e desempenho acadêmico, bem como, uma pesquisa longitudinal demonstrando como essa rede social se moverá no decorrer do tempo.

Por outro lado reconhece-se que considerar a simples manifestação comportamental ou a emissão de opiniões ou preferências pessoais através da aplicação de questionários, de forma isolada, implica em uma séria dificuldade de compreender a questão em sua complexidade. 


\section{Referências bibliográficas}

Burrell, G.; Morgan, G. (1998). Sociological paradigms and organisational analysis : Elements of the sociology of corporate life. Aldershot: Ashgate.

Burt, R. S.; Lin, N. (1976). “Network Time Series From Archival Records". In: Heise, D. R. (ed.). Sociologial Methodology. San Francisco: J ossey-Bass.

Coch, L.; French Jr, R.P (1948). "Overcoming Resistance to Change", Human Relations 1: 512-532

Deutsch, M. (1949). "A theory of Cooperation and Competition", Human Relations, 2(2), 129-152.

Edwards, J. (1991). "Cooperation and competition: Two sides of the same coin?", The Irish J ournal of Psychology, 12 (76-82).

Elias, N. (1994). A sociedade dos indivíduos. Rio de Janeiro: Zahar.

Everly, G. S. (1989). A clinical guide to the treatment of the human estresse response. New York: Plenum Press.

Emirbayer, M.; Goodwin, J. (1994). “Network Analysis, Culture and the Problem of Agency", American Journal of Sociology, v.99, n.6, p. 1411-54, May.

Goleman, D. (1995). Inteligencia emocional: a teoria revolucionaria que redefine o que e ser inteligente. Rio de Janeiro: Objetiva.

Granovetter, M. S. (1973). "The Strength of Weak Ties", American Journal of Sociology, v. 78, n. 6 (1361-1380).

Hanneman, R. A. (2001). Introduction to Social Network Methods. Riverside: University of Califórnia.

Kartzenbach J.R.; Smith D.K.(1993). The Wisdom of Teams. Boston : Harvard Business School Press.

Krebs, D. L. (1996). "The value of evolutionary perspectives on social relations among children: A commentary", International Journal of Behavioral Development, $19(75-80)$.

Lewin, K. (1965). Teoria de campo em ciência social. São Paulo: Pioneira. 
Lorrain, F.; White, H. C. (1971). "Structural Equivalence of Individuals in Social Networks", Journal of Mathematical Sociology, v. 1 (49-80).

Mailhiot, G B. (1970). “Dinâmica e gênese dos grupos: atualidade das descobertas de Mills" In: Theodore M., Sociologia dos pequenos grupos. São Paulo: Pioneira.

Marteleto, R. M. (2001). "Análise das redes sociais: aplicação nos estudos de transferência da informação", Ciência da Informação, Brasília, v. 30, n. 1 (71-81), Jan./Abr.

Moreno, J. L. (1962). Fundamentos de la sociometria. 1. ed. Buenos Aires: Paidós.

Morin, E. (1992). "From the concept of system to the paradigm of complexity", J ournal of Social and Evolutionary Systems, 15 (371-385).

Palmieri, Marilícia Witzler Antunes; Branco, Angela Uchoa (2004). "Cooperation, competition and individualism from a sociocultural constructivist perspective", Psicol. Reflex. Crit., Porto Alegre, v. 17, n. 2.

Parsons, T; Bales, R F.; Shils, E. A. (1970). Apuntes sobre la teoría de la acción. Buenos Aires: Amorrortu.

Rodrigues J.; Mérida F. (2006). UCINET 6.0 Guía Práctica de Redes Sociales. Universitat de Barcelona.

Schermerhorn Junior, J. R.; Hunt, J. G.; Osborn, R. N. (2003). Fundamentos de comportamento organizacional. 2. ed. Porto Alegre: Bookman.

Schillings, A. (2005). Processo de estresse em mestrandos. Dissertação do PPG Psicologia da Universidade Federal de Santa Catarina, Florianópolis.

Siegler, R. S. \& Crowley, K. (1991). "The microgenetic method: A direct means for studying cognitive development", American Psychologist, 46 (606-620).

Wasserman, S.; Faust, K. (1994). Social Network Analysis: Methods and Applications. Cambridge: Cambridge University Press.

White, H. C.; Boorman, S. A.; Breiger, R. L. (1976). "Social Structure from Multiple Networks. I. Blockmodel of Roles and Positions", American Journal of Sociology, 81 (730-779). 